УДК 37.02

\title{
АКМЕОЛОГИЧЕСКИЕ ПРИНЦИПЫ ПЕДАГОГИЧЕСКОЙ ДЕЯТЕЛЬНОСТИ
}

Ефремова-Шершукова Н.А., Шмакова Н.С., Исмаилов Г.М., Минеев-Ли В.Е., Пивоварова А.В.

ФГБОУ ВО «Томский государственный педагогический университет», Томск, e-mail:shna16@mail.ru

В данной статье речь идет об основных акмеологических принципах педагогической деятельности. Авторы дают определение акмеологии и акмеологических принципов, а также характеристику каждого из таких принципов применительно к педагогической деятельности. Кроме того, авторы данного исследования, помимо прочего, также кратко рассматривают основные этапы развития акмеологии как отрасли педагогической науки, акцентируя особое внимание на том, что ее развитие пришлось на тот период времени, когда стало ясно, что в качестве одного из направлений педагогической науки необходимо уделять особое внимание не только повышению качества предоставляемого практикующими педагогами образования, но также и качеству подготовки самих педагогических кадров. В результате проведенного исследования авторы приходят к выводу о том, что в настоящий период времени акмеологическим принципам педагогической деятельности должно уделяться повышенное внимание, поскольку именно данный подход находится в полном соответствии с современными требованиями к образовательному процессу Российской Федерации. Кроме того, необходимо отметить, что исследование авторов может лечь в основу более глубоких и детализированных разработок в данном направлении педагогической науки.

Ключевые слова: акмеология, педагогическая деятельность, акмеологические принципы, система образования, современные подходы, профессионализм педагогов

\section{ACMEOLOGICAL PRINCIPLES OF PEDAGOGICAL ACTIVITY \\ Efremova-Shershukova N.A., Shmakova N.S., Ismailov G.M., Mineev-Li V.E., Pivovarova A.V. \\ Tomsk State Pedagogical University, Tomsk, e-mail: shna16@mail.ru}

\begin{abstract}
This article is about the basic acmeological principles of pedagogical activity. The author gives the definition of acmeology and acmeological principles, as well as the characteristics of each of these principles in relation to teaching. In addition, the author of this study, among other things, also briefly examines the main stages of the development of acmeology as a branch of pedagogical science, focusing on the fact that its development was at a time when it became clear that as one of the areas of pedagogical science it is necessary to pay special attention not only to improving the quality of education provided by practicing teachers, but also the quality of training of teachers themselves. As a result of the study, the author comes to the conclusion that at the present time acmeological principles of pedagogical activity should be given special attention, since this approach is in full compliance with modern requirements for the educational process of the Russian Federation. In addition, it should be noted that the author's research can form the basis of deeper and more detailed developments in this area of pedagogical science.
\end{abstract}

Keywords: acmeology, pedagogical activity, acmeological principles, education system, modern approaches, professionalism of teachers

Современное российское общество переживает сегодня сложный период реформирования всех значимых систем. Ориентация на динамичное развитие общества предполагает усиленное внимание к проблемам образования, в частности к подготовке и повышению квалификации специалистов в области обучения и воспитания.

Подготовка педагогических кадров на современном этапе предполагает формирование у будущих педагогов акмеологических качеств и навыков высокого уровня. Высокий образовательный уровень должен обеспечиваться всеми уровнями современной системы образования. При этом педагогу принадлежит специфическая роль в связи с тем, что он выступает в качестве одного из ведущих участников процесса воспитания и обучения подрастающего поколения.
От компетентности и профессионализма педагогов непосредственно зависят такие факторы, как качество образовательного процесса и административный потенциал учреждения образования.

\section{Материалы и методы исследования}

В качестве основных методов исследования заявленной темы послужили такие, как аналитический (анализ теоретической и методической литературы по теме исследования), а также метод обобщений.

\section{Результаты исследования и их обсуждение}

Специфика педагогической деятельности заключается в том, что ведущим механизмом воздействия педагога на подрастающее поколение выступает он сам, его личностные характеристики. Подобная осо- 
бенность работы преподавателей актуализирует задачу повышения профессиональных качеств и личностного роста педагога. В связи с этим на современном этапе требуется пересмотр подходов к вузовской подготовке будущих педагогов, которые были разработаны ранее и функционировали до недавнего времени. Теперь перед вузами стоит задача подготовки педагогов, которые обладают способностями к выработке стратегически верного направления в образовательной деятельности, достижению заданных целей, эффективной рефлексии, творческому подходу.

В настоящее время стремление к интеграции становится одной из ведущих тенденций мирового развития. Данное направление становится актуальным не только на мировом уровне, но и затрагивает каждую личность в отдельности на уровне социальных институтов и внутреннего личностного развития.

В связи с этим современная система вузовского обучения в значительной мере ориентирована на подготовку кадров, которые обладают набором характеристик, необходимых для достижения высоких результатов в предстоящей профессиональной деятельности. Это должны быть кадры, которые способны к эффективной социализации, творческому подходу, рефлексии и профессиональной конкурентоспособности.

Акмеология представляет собой достаточно молодую научную дисциплину, сформировавшуюся в результате новых потребностей общества, возникших в XX в. данная наука посвящена изучению способов, закономерностей и инструментов достижения вершин в различных сферах деятельности человека. «Акме» представляет собой слово греческого происхождения и означает апогей, высшую точку развития человеческой личности. «Акме - этап наивысшего расцвета творческой деятельности» [1].

На современном этапе акмеология как научная дисциплина ориентирована на исследование многоаспектной проблемы личностной самореализации с гуманистической и прогрессивной точки зрения. Кроме того, акмеология рассматривает проблемы саморазвития, творчества и личностной профессионализации. В ряде сфер акмеология как научная дисциплина сближается с психологией, педагогикой и другими науками, за счет чего она формируется как интеграционная отрасль знания.

Для акмеологии как относительно молодой науки особенно значимыми вопросами являются проблемы успешности, профессионального роста, саморазвития и самоактуализации человека. Наиболее полно акмео- логия как наука о самореализации человека начала раскрываться в 1990-е гг.

Современные исследования в области акмеологии базируются на обширном комплексе теоретических работ таких отечественных ученых, как В.Н. Максимова, А.А. Деркач, Н.В. Кузьмина, В.Г. Зазыкин.

Особо необходимо отметить значительный вклад в исследование акмеологических проблем А.А. Бодалева, который является автором ряда работ, посвященных акмеологии как новой парадигме образования. В частности, исследователь отмечал, что «предметом акмеологии выступают субъективные и объективные факторы, которые, в тесном взаимодействии, препятствуют либо содействуют прогрессивному развитию взрослого человека, а также механизмы и закономерности, открывающие перед личностью возможности достижения вершин, которые обозначаются понятием «акме» [2].

В настоящее время акмеологический подход может считаться одним из наиболее перспективных и прогрессивных для образовательной системы. Исследователи полагают, что «суть акмеологического подхода состоит в реализации комплексного исследования и восстановления целостности субъекта, достигающего стадии зрелости. На этой стадии субъектно-деятельностные, личностные и индивидуальные черты исследуются во взаимосвязях и диалектическом единстве» [3].

Акмеологический подход к технологиям воспитания и обучения, содержательному компоненту образования, управлению высшей школой выходит в настоящее время на первый план. Подобный подход становится фактором повышения качества образовательной системы и усовершенствования технологий воспитания и обучения в вузе. Познавательные мотивы приобретают значение систематизирующих факторов, а процесс обучения переходит на уровень внутренней потребности личности. Ведущей формой деятельности личности становится переосмысление действительности на творческой основе.

Акмеологические методики и приемы позволяют использовать эффективные формы достижения профессионального и личностного успеха. В настоящее время становится очевидной значимость акмеологического подхода в административном и учебно-воспитательном процессе вузовского образования. Подобное обстоятельство непосредственно взаимосвязано с социальным заказом, который выдвигается обществом к выпускникам высших учебных заведений. Ожидается, что по окон- 
чании вуза общество получит креативных, коммуникабельных, самостоятельно мыслящих личностей, которые обладают способностями построения индивидуальной модели развития и навыками эффективной профессиональной деятельности.

Актуальность акмеологии на современном этапе связана с повышенным интересом к образованию и педагогике. В последние годы расширяется и углубляется процесс изыскания наиболее эффективных механизмов и способов, оказывающих воздействие на качество образования, прежде всего в рамках высшей школы. На современном этапе генерируются обновленные педагогические технологии, так как к настоящему времени осознана недостаточная актуальность традиционной образовательной системы. Старая система не отвечает обновленным экономическим и общественным условиям и требует оптимизации.

Категориальный и методологический аппарат акмеологической науки в настоящее время развивается, совершенствуются технологические и методические приемы и инструменты. Все это открывает широкие возможности в деле повышения качества образования, прежде всего вузовского.

Акмеология представляет собой отрасль научного знания, которая сформировалась на стыке гуманитарного, обществоведческого и естественнонаучного знания. Многоаспектность данной научной дисциплины связана, прежде всего, с тем, что она исследует способы, закономерности и инструменты достижения вершин в различных сферах деятельности взрослого человека, а также саморазвитие, творчество и личностную профессионализацию.

На современном этапе акмеология как научная дисциплина подразделяется на несколько направлений. К таким направлениям правомерно отнести: спортивную, военную, педагогическую, управленческую акмеологию.

Необходимо отметить вклад отечественных исследователей в развитие отдельных направлений акмеологии. Например, в исследовании В.Н. Максимовой «Акмеология: новое качество образования» обращается особенное внимание на педагогическую акмеологию. «Акмеология образования изучает условия и факторы достижения высокого качества образовательных систем и развития субъектов процесса образования: ученика и педагога» [4].

Для современной отечественной системы вузовского образования качество образования приобретает особенное значение, формируя обновленную парадигму развития высшей школы в нашей стране.
Качество образования - это комплекс его свойств, определяющий адаптацию образования к реализации социальных целей по формированию и развитию личности.

Современные акмеологические технологии и методики ориентированы на повышение профессионализма, развитие личностного потенциала человека, самореализацию, усовершенствование адаптационных способностей и развитие рефлексии. Так как акмеология выступает в качестве научного знания, имеющего интегрированный характер, акмеологические технологии и методики разрабатываются на стыке гуманитарных и естественных наук.

На современном этапе акмеологические технологии имеют следующую структуру:

- цель и задачи технологии;

- методологическая основа;

- принципы разработки;

- условия технологического процесса;

- анализ конкретной ситуации;

- характеристики субъекта и объекта технологии, особенности их взаимодействия;

- этапы, приемы (стратегические, тактические) достижения цели;

- способы прогнозирования результатов;

- внедрение [5].

Кроме того, необходимо отметить, что в настоящее время акмеологические технологии отличаются значительным разнообразием, причем основными из них можно назвать следующие:

- игровые (дидактическая игра, технологии игромоделирования);

- технологии психоконсультирования;

- тренинговые технологии;

- технологии развивающего обучения;

- технология личностно-ориентированного обучения;

- метод проектов [6].

Формирование педагогического профессионализма в настоящее время предполагает повышенную степень развития проектировочных умений и навыков. Педагог должен обладать развитыми способностями к моделированию, прогнозированию, мониторингу и диагностике педагогического процесса.

Значимость проектировочных навыков для педагога-акмеолога в настоящее время обусловлена необходимостью определения профессиональных задач, достижение которых связано с повышением мастерства и профессиональным ростом.

Современная акмеология в своем развитии сформулировала ряд основополагающих принципов, в качестве основных из которых можно назвать следующие:

- принципы личностного развития в направлении к достижению профессиона- 
лизма. В данную группу принципов могут быть включены принципы: активности, рефлексивности, оптимальности, формирования позитивной Я-концепции личности, субъекта и субъектности, моделирования;

- принципы изучения и анализа продуктивной педагогической деятельности и ее субъекта. В данную группу принципов могут быть включены принципы: комплексности, взаимодействия, развития, системности, детерминизма [7].

Строгое соответствие данным принципам позволяет надеяться на формирование и развитие у учащихся высшей школы навыков, умений и качеств, способствующих в дальнейшем эффективной профессиональной деятельности и достижению высоких личностных результатов.

В качестве одного из ведущих компонентов проектировочной культуры педагога с точки зрения современной акмеологии выступает целеполагание. Выдвижение значимых жизненных целей потенциально несет в себе для человека творческий элемент. Но не все люди могут реализовать подобные тенденции. Выделяются три основные категории людей. Для первой группы характерно пассивное ожидание, они не склонны к процессу активного целеполагания. В противоположность данной категории, существуют личности, выдвигающие значимые цели самостоятельно, на основе собственных ценностей и установок. Промежуточная категория людей характеризуется наличием черт обеих рассмотренных выше групп.

Таким образом, становится очевидным, что одним из ведущих компонентов профессиональной культуры учителя становится на современном этапе способность к творчеству.

Рефлексивные и аналитические способности выступают в качестве не менее значимых компонентов профессиональной культуры современного педагога. В рамках этого умения речь идет, прежде всего, о способности педагога к обобщению и систематизации собственного педагогического опыта, профессиональной рефлексии, выделению наиболее значимых и перспективных направлений личностного роста. Уровень развития у педагога рефлексивных и аналитических способностей оказывает непосредственное воздействие на результативность педагогического труда и эффективность методической работы. Таким образом, в конечном итоге данные характеристики педагога становятся важным фактором повышения качества образования.

Особенная роль на современном этапе принадлежит также здоровьесберегающе- му фактору. Здоровье взрослого человека выступает как ценность, основы которой закладываются в раннем возрасте. Современная трактовка категории «здоровье» предполагает интегративный подход. Это означает, что духовное и нравственное благополучие личности также является компонентом здоровья. Полноценное здоровье должно включать в себя нравственное, социальное, психическое и соматическое.

В акмеологии категория «акме» применяется и в более узком понимании, как достигнутый личностью наиболее высокий жизненный и профессиональный уровень, когда поведение человека оказывается отмечено наиболее ярким поступком, имеющим позитивную, социально значимую окраску. На таком этапе подъема деятельность человека проявляется в максимально возможном и получающем духовное либо материальное выражение в определенных итогах его творчества.

Образование, соответствующее современным стандартам качества, предусматривает комплекс таких свойств и черт объекта, которые определяют собой его адаптивные возможности в отношении осуществления социальных целей. Данные цели в настоящее время связаны, прежде всего, с процессами становления и личностного развития человека в качестве носителя таких свойств, как воспитанность, общая культура, обученность, выраженность физических, психических и социальных аспектов личности.

Достижение уровня качественного образования в настоящее время должно выступать как интегративная цель всех уровней и структурных частей системы образования. Ключевым звеном современной образовательной системы правомерно считать педагога в качестве одного из ведущих участников процесса воспитания, обучения подрастающего поколения и носителя административного потенциала учреждения образования.

\section{Выводы}

Таким образом, можно сделать общий вывод о том, что акмеология на современном этапе выступает в качестве научного знания, имеющего интегрированный характер, формирующегося на стыке таких научных дисциплин, как психология, педагогика и теория управления. Сочетание в методологии и категориально-понятийном аппарате современной акмеологии основ гуманитарных и естественных наук способствует существенному изменению акцентов в области профессиональной подготовки специалистов педагогического профиля. При акмеологическом подходе делается акцент 
на формирование креативных, коммуникабельных, самостоятельно мыслящих личностей, которые обладают способностями построения индивидуальной модели развития и навыками эффективной профессиональной деятельности.

Развитие акмеологических аспектов в общей структуре вузовской педагогической подготовки открывает широкие возможности по поиску выпускниками вузов индивидуальных путей продвижения к профессионализму. Помимо этого включение акмеологических аспектов в систему педагогического обучения в вузах способствует росту в педагогическом труде креативности и творчества, расширяет представления студентов о педагогическом мастерстве.

Ставшие к настоящему времени компонентом учебно-воспитательного процесса в вузе, акмеологические принципы открывают широкие возможности по формированию новой модели взаимодействия и конечного результата деятельности обучающегося и педагога.

\section{Список литературы}

1. Акмеология: учебник / Под ред. А.А. Деркача. М.: Издательство РАГС, 2006. $211 \mathrm{c}$

2. Зобнина Т.В. Акмеологические аспекты в преподавании педагогической психологии // Электронный журнал «Психологическая наука и образование». 2010. № 1. [Электронный ресурc]. URL: http://psyjournals.ru/psyedu ru/2010/ n1/26651_full.shtml (дата обращения: 02.09.2019).

3. Панасюк В.П. Школа и качество: выбор будущего. СПб.: КАРО, 2003. $240 \mathrm{c}$.

4. Тюрин К.Г., Степнова Л.А. Акмеологические способности как средство реализации самопреобразующей деятельности // Вестник РУДН, серия Педагогика и психология. 2016. № 2. С. 19-26.

5. Куратова О.А., Дабылтаева Р.Е. Акмеологический подход как необходимое условие повышения качества образования // Вестник КазНПУ. 2016. [Электронный ресурс]. URL: https://articlekz.com/article/19437 (дата обращения: 02.09.2019).

6. Натаров В.И. Рационализация состояния сознания как развитие акмеологической адаптации // Вестник психосоциальной и коррекционно-реабилитационной работы. 2011. № 4. С. 58-62.

7. Исмаилов Г.М. Самообразование и творческое развитие личности в процессе подготовки будуших учителе технологии // Развитие педагогического образования в России: материалы II Всероссийской науно-методической конференции с международным участием / отв. ред. Е.В. Гребенникова. Томск: ТГПУ, 2019. С. 273-279. 